\title{
Defining the Gross Cost and Net Cost Options for New Delhi Public Transport
}

\author{
Aaron Windecker \\ Duke University
}

\begin{abstract}
$\overline{\text { Abstract }}$
Increasing the use of public bus transportation and decreasing the use of private modes is the remedy for New Delhi's congested streets and polluted air. To achieve this, the provisioning of bus services in New Delhi should be privatized to reduce the financial burden on the government and augment capacity. Regulation of the privatized system will be needed to improve safety; prevent private operators from concentrating only on denser routes; improve reliability; punctuality; and other standards of quality; rationalize fares; and improve network design. This article discusses each of these goals and assesses the applicability in the New Delhi context of the different privati-ation models used internationally to meet these goals. Two composite strategies are recommended for meeting all of the goals: the gross cost option and the net cost option.
\end{abstract}

\section{Introduction}

New Delhi is facing a serious transportation crisis due to the increasing shift toward private means of transportation, in part because of the relative high per capita income of the city and poor traffic management, which has lead to congested roads and unacceptable levels of air pollution. An effective way to reverse the trend toward increased congestion and air pollution is to increase the role of 
public transport in New Delhi (TERI 2000b). Unfortunately, New Delhi's public transportation sector, comprised of public and private buses, is not currently up to the challenge. New Delhi's public bus company, the New Delhi Transport Corporation (DTC) is crippled by large operational losses (TERI 2000b). And. New Delhi's private buses are infamous for their poor safety record. New Delhi's public transportation sector needs to be privatized and restructured.

Privatizing should reduce the financial burden on the government and augment capacity. Regulation will be used to improve safety; prevent private operators from concentrating only on denser routes; improve reliability, punctuality. and other standards of quality; rationalize fares; and improve network design. This article addresses each of these goals and assesses the applicability in the New Delhi context of the different privatization models used internationally. Two composite strategies are recommended for meeting all of the goals: the gross cost option and the net cost option.

The gross cost option requires the government authority to set the routes operated and the fares charged. The fare revenue, however, accrues to the government authority, which then pays the private operators (PO) an agreed-upon amount per kilometer traveled. This way, even though each route can be operated by multiple PO, the PO do not have any incentive to recklessly race others to bus stops in order to gain more passengers. Furthermore, the PO are not hurt by fares that do not correspond to costs. The government authority awards the routes via competitive tender to the lowest bidder. Preference is given to PO that have achieved high standards of quality. This prevents PO from concentrating only on dense routes and provides the PO with the incentive to improve quality.

The net cost option allows PO to keep the fare set by the government. The government authority sets the routes and assigns each route via competitive bid to the PO requiring the least amount of subsidy or willing to pay the greatest fee. Again, the government authority can give preference to PO that have achieved high standards of quality. This provides the PO the incentive to improve quality. Since each route is contracted out to a single PO, the PO need not compete for passengers on the route. 


\section{Background of Public Bus Transportation in New Delhi}

Public bus service in New Delhi is provided in three ways. The governmentowned DTC operates its own buses and hires private buses under its kilometer scheme. Under this scheme, fares accrue to the DTC while the PO run the route assigned to them and are compensated on a per kilometer basis. Public bus serrice is also provided by PO running under the Blueline scheme. The State Transport Authority (STA) issues permits and sets routes and fares for the Blueline buses. Blueline services outperform the DTC on most physical parameters. achieving higher fleet utilization and lower number of staff per bus (TERI 2000b). The DTC is currently having severe financial difficulties, having accumulated losses of 1.85 billion rupees in 1998/99 (TERI 2000b). Unfortunately, the Blueline services have a poor road safety record and poor consumer satisfaction. This is a result of New Delhi being ineffective in regulating the large number of private operators and of Blueline operators neglecting quality and overworking their crews (TERI 2000b).

\section{Privatization}

The purpose of privatizing is to improve the financial performance of the public transport sector.

\section{Reduce the Financial Burden}

The DTC lost 2072.96 million rupees in 1999/2000 alone. It has an accumulated loss of 1.85 billion rupees as of 1998/99 (TERI 2000b). According to Agarwal (1997), these losses are attributed to:

- the large number of idle employees;

- large number of overaged buses;

- high instances of avoidable breakdown;

- high downtime of buses;

- free travel by policemen, students, DTC employees, and their friends;

- underutilization of buses;

- high staff-to-bus ratio;

- cost-overruns;

- high operating costs;

- red tape; 
- bureaucratic delays; and

- lack of professional management and autonomy.

These are all symptoms of inefficient management of the DTC.

\section{Unbundle Operations to Reduce the Financial Burden}

The idea is that a PO would be able to provide a more efficient and lowercost bus service than a public company. Thus, switching from a public company to POs would increase the efficiency of public transportation, which would lower the financial burden on the government. This seems to be the case currently as the kilometer-scheme buses incur relatively lower losses than the DTC's own buses (TERI 2000b). The Blueline buses have better fleet utilization (93\% compared to $82.6 \%$ ) for the DTC, and lower number of staff per bus (4.6 compared to 9.56 for the DTC; TERI 2000b). The theory behind this is that operations that are not natural monopolies are better left to the market where the forces of competition will make them more efficient. Charles Lave uses this idea as the foundation for his argument that policymaking should be separated from operating. He sees the role of the government authority as arranging or sponsoring public transportation rather than supplying the transportation itself (Lave 1985).

In the case of New Delhi, this idea should be applied by unbundling the DTC's operations into four parts: city buses, interstate buses, repairs and maintenance facilities, terminals and stations. The operation of city buses and of the repairs and maintenance facilities should be privatized. Interstate buses should be left as a public entity until the state-to-state reciprocal agreements that they operate under expire. However, the operation of terminals and stations should remain publicly controlled because this is a natural monopoly.

\section{Augment Capacity without Government Investment}

The number of buses operating in New Delhi would have to be increased by about 45 percent (calculated based on data from TERI $2000 \mathrm{~b}$ and TERI 2000a) to achieve the 75 percent modal split in favor of public transportation that the Planning Commission and the Government of National Capital Territory, New Delhi, have recommended. The private sector can augment capacity due to increased efficiency (TERI 2000a). Being able to do more with 
less allow s private operators to run routes otherwise unprofitable to the public sector, or to increase the frequency and so decrease the load on each bus. International experience shows this. Deregulation has increased the number of buses in Morocco (Gomez-Ibanez and Meyer 1993). In Istanbul and Bangkok, PO run routes that the public sector would find uneconomical to operate (Gomez-Ibanez and Meyer 1993). Deregulation led to an increase in fleet size in Santiago, Chile, from 1983-1993 (Gomez-Ibanez and Meyer 1993). However, the private sector can be expected to augment capacity only as long as it is profitable to do so. The United Kingdom outside of London increased its capacity by 26 percent through deregulation. The tradeoff, however, was an increase in fares by 23 percent. London was able to increase capacity by about 29 percent, and reduce subsidy by 70 percent. but not without increasing fares (Armstrong-Wright 2000). The bottom line is that besides increasing efficiency. augmenting capacity must be paid for either by patrons in the form of higher fares or by the government in the form of subsidies.

\section{Regulation}

The purpose of regulation is to create an effective regulatory framework for the public transportation sector.

\section{Improving Safety}

The privately operated stage carriage buses (Blueline) of New Delhi are infamous for their poor safety record. The results of a survey presented in the Indian Journal of Transport Management show that 84.47 percent of the respondents ranked these Blueline buses as poor in safety. Unfortunately, it also showed that 27.78 percent of the respondents ranked the buses run by the DTC, a public corporation, as having poor safety also (Goel 2000). The main cause of this poor safety record is the competition over passengers. $\mathrm{PO}$ that run on the Blueline scheme of New Delhi are especially known for racing to reach the next bus stop before the competition in order to capture more passengers and so reap a higher profit. This happens because many different PO as well as the DTC operate on the same route. Buenos Aires faces the same problem of aggressive driving by PO (Salvucci 1997). The desire to cut costs is also a large contributor to the problem. Despite the STA's regulation that buses have two 
drivers, more than 50 percent of drivers worked 12 to 16 hours a day. Furthermore, the quality of the drivers is questionable, as 87.5 percent have not had formal driving training and they generally have low levels of education (Dhingra and Savant 1998). Methods for solving the two problems of passenger capture and excessive cost cutting are addressed below.

Competition for the Market. J. Walters suggests that there be competition for the market, but not in the market. Instead of having several operators competing for passengers on the same route, operators would compete to be awarded the concession for the whole route (Walters 1998). Bus drivers would be less motivated to resort to aggressive driving and instead be more concerned with improving the quality of their service in order to win future concessions. This could also ameliorate the problem of excessive cost cutting. Employing untrained and overworked drivers decreases the quality of service provided in the form of increased accidents and poor driver conduct. If a PO was competing with other PO for the rights to a concession, then the PO would endeavor to increase quality even if that meant higher costs. This solution requires that the government authority ensure that concessions are awarded competitively and with an emphasis on safety and quality. Not only would this require a certain standard of monitoring to assess the performance of the PO, but also a large amount of political will. It is essential that the government authority have the political will to punish unsatisfactory operators; otherwise this system will degenerate into nothing more than a patchwork of local monopolies. This system of competitive concessions has been used successfully in both Hong Kong and Santiago, Chile (ArmstrongWright 2000). Unfortunately for this model, in New Delhi, law allows an operator to own only between one and five buses; thus, he would not be able to service a whole route unless that law is repealed.

Gross Cost Model. The second way in which to solve the safety problem is to use the gross cost model. In this model, ticket revenue accrues to the government authority, which in turn pays PO a per kilometer fee. This takes away the PO's incentive to increase passenger load and so there is no reason for them to engage in reckless driving. Since the DTC already uses the gross cost model for its kilometer-scheme buses, adopting this model would not require instituting 
something new, but rather just expanding a system already in place. Interestingly, during March 1998, March 1999, and February 1999, the rate of accidents per $100.000 \mathrm{~km}$ was lower for kilometer-scheme buses than DTC-operated buses (New Delhi Transport Corporation 1999). However, without the incentive to attract customers, PO are less likely to make improvements to their service that would attract customers. This requires strict supervision to ensure that the operators are running their routes as scheduled and are correctly recording fares collected. These concerns caused London Transport to change from the gross cost model to the net cost model where PO keep the fares (Armstrong-Wright 2000).

Most important to any effort to improve the safety of public transportation is an effective regulatory body. Regulations concerning drivers' qualifications and conduct must be enforced. If nothing else, the STA should be given better means by which it can enforce regulations on the PO.

\section{Prevent PO from Concentrating Only on Denser Routes}

PO prefer to concentrate on the more heavily traveled routes, while neglecting the less traveled ones. This can be seen in the case of New Delhi, where the Blueline operators who had been assigned less-traveled routes asked that the STA change their routes. This is counter to the governments' desire to have public transport available for all of its citizens, not just those along the denser routes. The sections below discuss means of addressing this problem.

Cross Subsidization. The first means of solving this problem is cross subsidization. This model assigns a mix of economic and uneconomic routes to each operator. The profit that PO make on dense routes makes up for the loss on the less-traveled routes. This model has been adopted by Hong Kong (Armstrong-Wright 2000). However, this would be difficult to do in the case of New Delhi because most PO own between one and five buses and so would not be able to service more than one route. Even if the number of buses owned by each operator increased, this model would be complicated to implement because the government authority would have to asses the profitability of each route so as to balance the profitable routes with the unprofitable routes.

Cross Subsidization and PO Associatives. Korea has overcome this problem by organizing the PO into large associatives. These associatives are assigned 
a mix of routes, and the PO take turns running the profitable and unprofitable routes assigned to their associative (Gomez-Ibanez and Meyer 1993). Howerer. because of the large number of PO in New Delhi, forming these associatives would require a lot of time and effort on the part of the government.

Competitive Tenders. Another way to correct for the varying profitability of routes is to use competitive tenders, whereby PO bid for the amount of subsidy they would require to run each route. In the case of dense routes, the bids would be negative so the PO would pay for the privilege of running those routes. Variations of this model are used in Adelaide, Australia (Radbone 1997), Istanbul, Bangkok (Gomez-Ibanez and Meyer 1993), London, and the United Kingdom outside London. In the United Kingdom, for example. local authorities offer subsidies for unprofitable routes to the lowest bidder but there is no bidding on profitable routes (Armstrong-Wright 2000).

Gross Cost Model. The fourth way to solve this problem is to contract out every route on a gross cost model. The profit made by the government on the dense routes offsets the loss on the less dense routes. Since the PO do not keep the fare, but instead receive a fee for the distance traveled, there is no preference for denser routes. On the other hand, there could be a preference for the less-dense routes because the bus would move faster, cover more distancecollecting more money from the government authority. To correct for this preference, the routes would be assigned to the PO who would accept the lowest compensation per kilometer for each route. PO would be willing to accept lower payment per kilometer for the less congested routes because they would be able to cover more distance.

\section{Improve Reliability, Punctuality, and Overall Quality}

Another important concern is the reliability, punctuality, and overall quality of the public transportation. These aspects need to be improved if public transport is to compete successfully against two-wheelers, three-wheelers, and the private car. According to a survey presented in the Indian Journal of Transport Management, 38.88 percent of those polled said that the DTC had poor punctuality; and 29.39 percent noted the Blueline had poor punctuality. Of those surveyed, 41.66 percent said that the DTC had poor dependability; and 41.66 percent 
complained of poor cleanliness. The DTC was ranked as poor for overall service by 48.40 percent of the respondents. Privately operated buses fared no better; they were ranked as poor by 48.50 percent (Goel 2000).

Reliability, punctuality, and overall quality can be improved though quality incentive contracts and competitive tenders.

Quality Incentive Contracts. London is trying to get PO to improve the quality of service provided by using quality incentive contracts. Under these contracts, the PO receive increased payments from the government authority for positive quality achievements, and receive fines when quality standards are not met (Armstrong-Wright 2000).

Competitive Tenders. By placing routes up for rebid every few years and awarding high-quality $\mathrm{PO}$ the routes of the poor-quality PO, the government authority creates an incentive for the PO to run a high-quality service. Hong Kong and Santiago, Chile, both use this model (Armstrong-Wright 2000).

With both of these models, monitoring is important. The government authority must be able to assess the quality of each individual PO to determine whether to continue or terminate their contract or to give quality bonuses. However, the competitive tender model would be easier to manage. Under the competitive tender model, it would not be necessary to draw up more complex quality contracts, negotiate with each PO, fine the PO, and resolve disputes over fining that would inevitably occur. Instead, the government authority could simply refuse to renew the contract of poorly-performing PO. To reduce the burden on the government authority, the competitive tender model should be given preference in the case of New Delhi.

The gross costs model calls for an even greater need for monitoring. Because the PO have no motivation to increase ridership, there is the danger that the PO would not even complete the route assigned to them, much less maintain a high-quality service. It is for these reasons that London abandoned the gross cost model in favor of the net cost model (Armstrong-Wright 2000).

\section{Rationalize Fares}

Governments decide to cap tickets prices to make them affordable to the less well-off, to encourage the use of public transport over private transportation, 
or to give concessional travel to certain groups of people (e.g., students). It is politically difficult to increase fares, even when the cost of providing the service increases. In New Delhi, there is no set formula for increasing fares when inputs increase nor is there a periodic assessment of the fares. The fare rate is determined by political rather than economic considerations (TERI 2000b). An increase in the PO's costs without a corresponding increase in fares results in a decrease of the PO's ability to maintain their vehicles, resulting in a decline in quality, which in turn causes ridership and revenue to fall. This is the case in Medellin, Colombia, where PO are not able to replace aging buses (GomezIbanez and Meyer 1993). Privatization efforts in Kingston, Jamaica, in 1983, resulted in the deterioration of quality and quantity (Armstrong-Wright 2000). Thus, while PO may be able to operate bus service more efficiently than the public company, they still need a certain amount of revenue to cover operating costs. maintenance, and fleet replacement. If fares are kept too low, the PO will not be able to replace or maintain their fleets. The following sections examine four ways to avoid this problem.

Periodic Fare Increase. Fares could be increased using parameters such as inflation and fuel costs. This is also known as the cost plus formula, whereby the fare is set equal to the cost of providing the service plus an acceptable rate of return minus an efficiency incentive factor.

Competitive Tenders with Variable Fares and No Subsidy. In this model. which was adopted by Hong Kong and Santiago, Chile, the government authority allocates routes to $\mathrm{PO}$ via competitive tenders. Criteria for selection include fares to be charged, age of buses, and quality of service to be provided (Armstrong-Wright 2000). This allows the government authority to make tradeoffs among quality, frequency, and fares. The fare is renegotiated every time the tenders are rebid. For New Delhi this could be more difficult because the large number of PO would make it difficult to individually determine the fare that each one could charge. It would also mean that there would be a large variation in fares across the City, which would be inconvenient for passengers. Furthermore. the government might not want to raise fares for political and social reasons.

Competitive Tenders with Variable Subsidy and Fixed Fares. Another solution is again to allocate routes to PO based on competitive tenders. Since the 
fares are fixed by the government, the PO bid on how much of a subsidy they will need or how much they would be willing to pay the government to run the route at those levels of fares. Internationally, this model is most often used by governments to get PO to run uneconomic routes for social reasons, as is the case outside London (Armstrong-Wright 2000), Morocco (Gomez-Ibanez and Meyer 1993). and Bangkok. Bangkok is the only one of these areas to collect a fee for allowing PO to run on the more profitable routes (Ray 2000).

Gross Cost Model. In this model, the fare revenue accrues to the government. which pays the PO on a per kilometer basis. The government sets the fares as it likes because the $\mathrm{PO}$ are insulated from the revenue risk.

\section{Improve Network Design}

The network or route design is important for a successful public transportation system. Unfortunately, in New Delhi the responsibility for route design is split between the DTC and the STA and "there is no systematic exercise for network and route design." The result is that "routes are decided on the basis of public pressure and not on the basis of a scientific assessment of the demand" (TERI 2000b). Three models for assigning the responsibility for network design are discussed below.

Responsibility of the Government. Designing the network can be the responsibility of a single government authority-as has successfully been done in both London and Curitiba, Brazil. As for the institutional structure of this government authority, the TERI report, Restructuring Options for the Delhi Transport Corporation, recommends that an independent regulatory agency "would be best in the long-term interest of public transportation in New Delhi" (TERI 2000b). Both London and Curitiba employ an independent company controlled by the government. London Regional Transport is an independent company with a board appointed by the government (Armstrong-Wright 2000); Curitiba's public transportation is managed by Urbanization Agency of Curitiba (URBS), an independent company owned 99 percent by the government (Amsler 1998).

Responsibility of the PO. Design can be the responsibility of the PO, as in the United Kingdom outside London, where PO can run any routes they 
choose. However, PO have the tendency to concentrate on the more profitable routes while neglecting others. Decentralized decisionmaking led to a lack of information and confusion as PO frequently changed their routes.

Responsibility of Both Government Authority and PO. Design can be the responsibility of both the government authority and the PO. In Hong Kong. for example, the government works in consultation with the PO (ArmstrongWright 2000).

In New Delhi, the most appropriate division of responsibility is for the government authority to be solely responsible for designing the network. This is because currently all route planning is done either by the DTC or the STA. The PO each only have a few buses and do not have the expertise to carry out such planning so there is no benefit to devolving authority. Having the government authority design the network would also facilitate integration between the buses and the other modes of public transportation.

\section{Conclusions}

Several different suggestions have been presented for each of the goals of privatization and regulation (see Table 1). Based on the discussion above, suggestions that are clearly worse than the alternatives are eliminated. (Eliminated options are shown crossed off in the table.)

- For the goal of preventing PO from concentrating only on dense routes. the suggestion of cross subsidization is eliminated because in New Delhi most PO own between one and five buses and would not be able to service more than one route. The suggestion of cross-subsidization plus $\mathrm{PO}$ associatives is also eliminated because of the large government effort required to create the associatives.

- For the goal of improving reliability, punctuality, and overall quality, the suggestion of quality contracts is eliminated because of its complexity.

- For the goal of rationalizing fares, the suggestion of competitive tenders with variable fares and no subsidy is eliminated because of the large number of PO involved, variation it would cause in fares across the city, and the government might not want to raise fares for political reasons. 


\begin{tabular}{|c|c|}
\hline \multicolumn{2}{|c|}{$\begin{array}{c}\text { Table } 1 \\
\text { Eliminate Dominated Suggestions }\end{array}$} \\
\hline Goals & Suggestions \\
\hline $\begin{array}{l}\text { Reduce financial burden on } \\
\text { government }\end{array}$ & Unbundling and privatization \\
\hline $\begin{array}{l}\text { Augment capacity without } \\
\text { government investment }\end{array}$ & Privatization + fare increase or subsidy as necessary \\
\hline Improve safety & $\begin{array}{l}1 \text { route }=1 \text { operator } \\
\text { Gross cost }\end{array}$ \\
\hline $\begin{array}{l}\text { Prevent PO from concentrating only } \\
\text { on dense routes }\end{array}$ & $\begin{array}{l}\text { Erostizan } \\
\text { Competitive tenders } \\
\text { Gross cost } \\
\end{array}$ \\
\hline $\begin{array}{l}\text { Improve reliability, punctuality, and } \\
\text { overall quality }\end{array}$ & $\begin{array}{l}\text { Competitive tenders } \\
\text { Cons }\end{array}$ \\
\hline Rationalize fares & $\begin{array}{l}\text { Formula for fare increase } \\
\text { Gross cost } \\
\text { Competitive tenders with variable subsidy and fixed } \\
\text { fares }\end{array}$ \\
\hline Improve network design & $\begin{array}{l}\text { Responsibility of government only } \\
\text { Responsibitity of government }\end{array}$ \\
\hline
\end{tabular}

- For the goal of improving network design, the suggestions of making it the responsibility of the government and the PO and of making it the responsibility of only the $\mathrm{PO}$ are eliminated because currently the PO have no expertise, much less experience, designing route networks.

Looking at the three goals that have more than one remaining suggestion, we see that the gross cost model addresses all of them. Thus, the gross cost model forms its own option. In the gross cost option, each bus running a route can be operated by a different PO. The PO charge the fare set by the government authority, but do not keep the fare. Instead the fare is turned over to the government authority which pays the PO a set rate based on distance traveled. The government authority is solely responsible for setting the routes, which it then assigns to the lowest bidder, preventing PO from concentrating only on dense routes. Since the PO do not collect fares, they no longer have the incentive to recklessly race others to the bus stops to gain more passengers, and they are not hurt by 
fares that do not correspond to costs. The government authority can also give preference to PO that have achieved high standards of quality and can deny routes to PO that have poor standards of quality. This provides the PO the incentive to improve quality. Table 2 summarizes the gross cost option.

\begin{tabular}{|c|c|c|}
\hline \multicolumn{3}{|c|}{$\begin{array}{c}\text { Table } 2 \\
\text { Organize Remaining Suggestions into Distincts Options }\end{array}$} \\
\hline Goals & Gross Cost Option & Net Cost Option \\
\hline $\begin{array}{l}\text { Reduce financial burden on } \\
\text { government }\end{array}$ & Unbundling and privatization & Unbundling and privatization \\
\hline $\begin{array}{l}\text { Augment capacity without } \\
\text { government investment }\end{array}$ & $\begin{array}{l}\text { Privatization + fare increase or } \\
\text { subsidy as necessary }\end{array}$ & $\begin{array}{l}\text { Privatization + fare increase or } \\
\text { subsidy as necessary }\end{array}$ \\
\hline Improve safety & Gross cost & 1 route $=1$ operator \\
\hline $\begin{array}{l}\text { Prevent PO from } \\
\text { concentrating only on dense } \\
\text { routes }\end{array}$ & Gross cost & Competitive tenders \\
\hline $\begin{array}{l}\text { Improve reliability, } \\
\text { punctuality, and overall } \\
\text { quality }\end{array}$ & Competitive tenders & Competitive tenders \\
\hline Rationalıze fares & Gross cost & $\begin{array}{l}\text { Competitive tenders with } \\
\text { variable subsidy and fixed } \\
\text { fares }\end{array}$ \\
\hline Improve network design & $\begin{array}{l}\text { Responsibility of government } \\
\text { only }\end{array}$ & $\begin{array}{l}\text { Responsibility of government } \\
\text { only }\end{array}$ \\
\hline
\end{tabular}

Having already assigned the gross cost model to its own option, we can now ignore it to find the second option. There is only one remaining suggestion for all but one goal, rationalize fares, which has two. However, we see that competitive tenders will be used to solve two other goals: prevent PO from concentrating only on dense routes, and improving reliability, punctuality, and overall quality. Since competitive tenders are already being used, it makes sense to use them to rationalize fares as well. This solution allows the government authority the option of, for political reasons, not increasing fares at the expense of increased subsidies for routes that are rendered uneconomical by rising costs. The government authority also has the option of increasing fares and so decreasing subsidies. For these reasons we can eliminate the suggestion of formula for fare increase from the second option.

The second option is the net cost option. Unlike in the gross cost option. the PO keeps the fare set by the government. In this option, the government 
authority sets the routes and assigns each via competitive bid to a single PO. This would necessarily require the repeal of the law restricting a PO to owning no more than five buses. Since the PO is the only operator on the route, there is no dangerous competition between operators to reach the bus stop first. The government authority awards the route to the PO that is willing to pay the greatest amount, or would require the least amount of subsidy, to run the route. The government authority can also give preference to PO that have achieved high standards of quality, and can deny routes to PO that have poor standards of quality. This provides the PO the incentive to improve quality. Table 2 summarizes the net cost option.

\section{Comparing the Two Options}

In deciding between the two options a key concern is whether it will be possible to repeal the law preventing each PO from owning a large number of buses and so allow each route to be assigned a single operator. If not, then the net cost option will not be able to solve the safety problem. This makes the gross cost option much more favorable. This option is also favorable because it is easier to integrate fares among different operators and different modes with the gross cost model (Walters 1998). However, the gross cost option will require more monitoring because the $\mathrm{PO}$ will have no incentive to attract passengers or accurately collect fares. If the government authority cannot provide the required monitoring, then the use of the gross cost option will end in decreased quality, falling ridership, and increased costs to the government authority. If it is possible to assign each route to a single PO, then the net cost option is preferable because of the lower requirement for government monitoring and therefore a higher probability of success.

\section{Acknowledgments}

This article was written for and is being used in a project on restructuring public transport by the Tata Energy Research Institute (TERI) in New Delhi, India. The author would like to convey special thanks to Kaushik Deb, TERI's area convenor for urban and transport systems. 


\section{Endnote}

1. For a more complete description of the separation of the DTC, see the TERI report, Restructuring Options for the Delhi Transport Corporation (2000).

\section{References}

Agarwal, A. L. ed. 1997. Systems approach to Delhi transportation problems, need for and scope of. Proceedings of the National Conference on Delhi Transportation System in the 21st Century. Delhi: Netaji Subhas Institute of Technology.

Amsler, Yves. 1998. Urban public transport regulation and financing: International overview. In Urban transport policy: A sustainable development tool. Peter Freeman and Christian Jamet, eds: 963-970. Balkema, Rotterdam: 963-970.

Armstrong-Wright, Alan. 2000. Bus services: Deregulation and privatisation. Indian Journal of Transport Management (June): 421-436.

Delhi Transport Corporation. 1999. Operational statistics. New Delhi: Delhi Transport Corporation (March).

Dhingra, Kiran, and Sujata Savant. 1998. Implication of liberalisation of bus services: Case study of Delhi. In Urban transport policy: A sustainable development tool. Peter Freeman and Christian Jamet, eds.: 1029-1037. Balkema. Rotterdam: 1037.

Goel, Tripta. 2000. Urban bus transit system in Delhi: An assessment of the quality of service. Indian Journal of Transport Management (May).

Gomez-Ibanez, Jose A., and John R. Meyer. 1993. Going private: The international experience with transport privatisation. Washington DC: The Brookings Institute: $389-394$.

Lave, Charles, ed. 1985. Urban transit: The private challenge to public transportation. Pacific studies in public policy: San Francisco, CA: Pacific Institute for Public Policy Research: 272-275. 
Radbone, Ian. 1997. The competitive tendering of public transport in Adelaide. Fifth International Conference on Competition and Ownership in Land Passenger Transport. Leeds, UK.

Ray, Amit. 2000. Major issues on private participation in passenger transport and infrastructure. Indian Journal of Transportation Management (May): $345-358$.

Salvucci, Frederick P. 1997. Observations on the Buenos Aires experience with increased private sector roles in the production of commuter rail, transit and bus services. Fifth International Conference on Competition and Ownership in Land Passenger Transport. Leeds, UK.

TERI. 2000a. Developing a sustainable and environmentally sound transport system for Delhi. TERI Project Report No. 98UT42. New Delhi: Tata Energy Research Institute: 239.

TERI. 2000b. Restructuring options for the Delhi Transport Corporation. TERI Project Report No. 2000UT63. New Delhi: Tata Energy Research Institute: 89.

Walters, J. 1998. The role of institutional structures at metropolitan level in SA in organising public bus transport. In Urban transport policy: A sustainable development tool. Peter Freeman and Christian Jamet, eds: 901-909.

\section{About the Author}

Aaron Windecker (aww3@duke.edu) is an undergraduate student at Duke University, working toward a B.S. degree in economics and a B.A. degree in environmental science and policy. Though he is a U.S. citizen, Mr. Windecker has spent much of his life living in different parts of Asia, including New Delhi, where this article was written. As for the future, he hopes to maintain his international outlook while dealing with economic and environmental issues. 
